\title{
Inovasi Sistem Penyediaan Air Minum Berbasis Teknologi Tepat Guna Untuk Pesantren
}

\author{
Gede H. Cahyana ${ }^{1}$
}

\begin{abstract}
As an education institute, pesantren (a classical boarding school) has many of people. One of the primary needs is water for drinking, cooking, washing, and for ritual like jinabat bathing and wudhu. However, in some cases, it is not easy to get some clean water in pesantren and usually the water is bad in its quality. One pesantren perhaps used water ponding with poor quality, not sanitary and so not hygienis. Due to this problem, pesantren should apply an appropriate technology in its water supply system. After observation on water sources, transmission, distribution, pesantren must choose and fix its water treatment train. The option is an inovative of Roughing Filtration and Slow Sand Filter. Both of the filters potentially treat the water and reduct the turbidity of the water sources used to drinking, bathing, wudhu, cooking and so on. To realize the planning, members of pesantren should work together from the start of the project, i.e in initial idea, field survey, technical calculation, construction time, operation and maintenance. The fund or construction cost should be handled together.
\end{abstract}

Key words: water source, transmission, distribution, roughing filter, slow sand filter

If I were called in

To construct a religion

I should make use of ... water.

(Philip Larkin: Whitsun Weddings).

Tersebut adalah puisi yang menempatkan air setara dengan agama, bahkan dari airlah diciptakan agama. Ditulis oleh Philip Larkin, puisi ini menjadi bagian penting dalam khazanah lingkungan, khususnya peran air sebagai komponen lingkungan yang erat kaitannya dengan agama dan manusia. Dalam Surat Al Anbiyya: 30 ditegaskan bahwa segala yang hidup diciptakan dari air. Juga terbukti, 75 persen tubuh manusia disusun oleh air dan Al Qur'an menyebut kata air minimal 63 kali. Dalam perkembangan budaya tradisional, tingginya kesakralan air tampak dari ungkapan tirtha nirmala, tirtha

\footnotetext{
${ }^{1}$ Dosen Teknik Lingkungan Universitas Kebangsaan Bandung
} 
kamandalu, amrta njiwani (Sansekerta), maaul hayat (Arab), nectar-ambrosia (Yunani), the elixir of life, the liquid of life (Inggris), air suci (Indonesia).

Faktanya, air terlibat dalam semua kehidupan manusia, baik untuk minum maupun ibadah ritual. Namun air yang layak digunakan untuk minum dan ibadah tidak mudah diperoleh. Ada daerah yang banyak airnya tetapi keruh sehingga tak sedikit yang krisis air minum. Di pesantren pun demikian, banyak yang airnya digenangkan begitu saja di kolam dekat masjid lantas digunakan untuk mandi, cuci baju dan beras, juga wudhu. Meskipun sah, tetapi airnya tidak sehat dan tidak menyehatkan, malah membahayakan kesehatan santri termasuk pengasuhnya (kyai).

Kalau demikian, adakah cara untuk memperoleh air layak-minum, memenuhi syarat kesehatan dan murah dalam pembuatan unit pengolahnya? Tulisan ini memberikan opsi unit pengolah air minum yang jarang diterapkan di Indonesia dan untuk unit tipe tertentu belum ada terapannya di Indonesia. Dalam tulisan ini juga diberikan gambar inovasi pengolahannya yang belum pernah diterapkan di Indonesia, yakni hibrida antara Upflow Roughing Filter (URF) dan Slow Sand Filter (SSF). Satu kelebihan URF ialah kebutuhan lahannya relatif sempit dan pada unit SSF-nya disediakan mekanisme backfilling yang belum pernah dibuat pada unit serupa di Indonesia.

\section{Sistem PAM}

Sudah saatnya kehidupan pesantren, terutama yang di pelosok, tak lagi kumuh jika dilihat dari sainstek kesehatan lingkungan, tetapi sudah lebih peduli pada sanitasi, baik berupa sistem penyediaan air minum, penyaluran air limbah, persampahan, dan drainase air hujan. Hanya saja, keterbatasan ilmu, pengetahuan, dan teknologi, juga dana untuk pembangunannya menjadikan kondisi pesantren di perdesaan menjadi tertinggal dalam hal kesehatan lingkungan. 
Sebetulnya pesantren dapat dengan mudah memperoleh air minum asalkan ada sumber air bakunya, baik yang relatif jernih maupun yang sangat keruh dengan menerapkan teknologi lingkungan tepat guna (appropriate technology). Sistem penyediaan air minum dapat dilaksanakan dengan swadaya dan swakarya tanpa bantuan konsultan dan tanpa menunggu bantuan teknis dan uluran finansial dari pemerintah. Pesantren dihuni oleh banyak santri yang dapat bergotong-royong membangun sistem penyediaan air minumnya.

Bagaimana bentuk sistem penyediaan air minum (SPAM) yang tepat guna? Sistem PAM ini dapat dibagi menjadi empat bagian, yaitu sumber, instalasi, transmisi dan distribusi. Dari sisi rekayasa PAM yang meliputi aspek sumber daya air, teknologi instalasi, pola pipa dan hidrolikanya tentu butuh banyak waktu untuk mendesainnya. Apalagi kalau cakupan layanannya sangat luas, selain untuk pesantren juga untuk warga di sekitarnya. Pada SPAM pesantren ini yang dibutuhkan hanyalah hal-hal praktis implementatif, dapat diterapkan oleh santri yang belum mengenal formula hidrolika dan belum pernah belajar atau kuliah PAM.

Komponen SPAM dapat dibedakan menjadi empat bagian. Yang kesatu ialah sumber air (source). Biasanya berupa mata air, tetapi bisa juga sungai, danau, atau waduk. Yang ekonomis ialah mata air sebab kualitas fisika dan bakteriologinya sudah memenuhi baku mutu air minum. Secara kimia pun umumnya memenuhi syarat walaupun kadang-kadang konsentrasi besi, mangan, dan kesadahannya agak tinggi. Oleh sebab itu, yang lebih banyak menjadi masalah adalah soal keamanan dari gangguan manusia dan hewan (ternak). Untuk mencegahnya, di sekeliling bak penangkap mata air (Belanda: broncaptering) harus dipagari dan ada petugas yang rutin membersihkan dan mengontrolnya. Santri pun dapat dilibatkan dalam tugas ini secara bergiliran. 
Yang penting juga diketahui adalah kapasitas mata airnya dan ini bergantung pada jenis akifernya (aquifer, pepundi air). Juga dipengaruhi oleh posisi lapisan kedap (impervious layer) di dalam pepundinya, apakah berupa air tanah bebas (unconfined aquifer) ataukah air tanah tak bebas (confined aquifer). Hal ini pun ditentukan oleh parasitas (perviousness) pepundi, bukan oleh porositas (porosity) pasir. Yang terbaik ialah mata air dari air tanah tak bebas atau artesis (artesian spring: istilah yang merujuk pada Desa Artois di Prancis).

Yang kedua ialah instalasi. Kalau pesantren memanfaatkan air baku dari mata air, maka instalasi pengolahannya tidak perlu seperti yang dibuat oleh PDAM, berupa pengolahan lengkap (complete treatment) untuk air sungai yang keruh. Pesantren bisa menggunakan pengolahan praktis untuk air sungai yang relatif jernih, belum terkontaminasi pestisida seperti yang dijelaskan dalam bagian bawah artikel ini.

Yang ketiga adalah transmisi. Antara lokasi mata air dan daerah permukiman pasti ada jaraknya, sependek apapun itu. Jarak ini harus ditempuh dengan memasang pipa penyalur air dari mata air ke bak penampung di pesantren atau di lokasi tertentu yang tepat secara hidrolika. Pemipaan transmisi ini hendaklah dipasang di lokasi aman, di sisi jalan agar mudah dikontrol dan diperbaiki. Kalau airnya berupa air baku, biasa disebut pipa transmisi air baku. Kalau yang dibawanya air bersih, yaitu air olahan, baik yang hanya diberi kaporit maupun diolah secara lengkap, biasa disebut pipa transmisi air minum.

Berkaitan dengan transmisi ini, catatlah lokasi dan lebar sungainya agar dapat dihitung kebutuhan jembatan pipanya. Tetapi usahakan hindari sungai agar tidak ada jembatan pipa sehingga murah biayanya. Letakkan pipa mengikuti alur atau profil tanah, hindari lokasi yang sulit dijangkau. Sediakanlah alat penguras (blow off) di lokasi dekat sungai atau selokan dan dipasang di tempat terendah untuk membuang lumpur (kalau ada) 
dan membuang air kalau ada kerusakan (darurat, emergency). Bergantung pada elevasinya, perlu dibuatkan bak pelepas tekanan (BPT) di tempat tertentu di sepanjang pipa transmisi.

Yang keempat, distribusi, yaitu daerah layanan (servis), yakni semua lokasi di pesantren, mulai masjid, asrama putra dan putri, dapur, dan rumah kyai (ustadz).

\section{Pelaksanaan Kerja}

Semua warga pesantren sebaiknya terlibat dalam proyek ini, mulai dari iuran, perencanaan, pekerjaan fisik, dan pembelian barang. Santri senior dapat berperan sebagai "konsultan" perencana untuk menghitung panjang pipa, diameter, aksesoris pipa, lokasi bak penampung, kran umum, dan kebutuhan konstruksinya. Semua jenis pekerjaan ini relatif mudah dilaksanakan. Berikut ini diberikan tahap kerjanya.

Tahap satu, sumber air. Sumber air perlu dipilih kalau ada lebih dari satu sumber. Pertimbangkanlah debitnya kemudian pilih yang terbesar. Debit terbesar ialah debit minimum menjelang musim hujan dan harus lebih besar daripada kebutuhan air total pesantren. Perlu diketahui juga debit reratanya. Debitnya ini dapat dihitung dengan mudah, menggunakan ember yang sudah diketahui volumenya dan arloji atau stopwatch. Tampunglah airnya sambil diukur dengan arloji atau stopwatch. Volume ember dibagi kebutuhan waktu untuk mengisinya sama dengan debit.

Dari beberapa tipe mata air, prioritas pertama ialah artesian spring, lalu gravity spring, dan surface (atmospheric) spring. Yang dipilih adalah mata air yang terdekat dengan pesantren agar murah biaya pipa dan galiannya, juga mudah dipantau. Usahakan yang lebih tinggi elevasinya agar mampu mengalir ke tempat terjauh di pesantren. Dalam pembuatan broncaptering, berhati-hatilah agar tinggi muka airnya tidak bertambah karena dapat mengalihkan titik keluar airnya, pindah ke lain tempat. 
Tahap dua, hitunglah kebutuhan air pesantren untuk mengetahui besaran sistemnya, yaitu debit air yang mencukupi kebutuhan semua orang di pesantren. Lakukanlah survei sederhana berkaitan dengan jumlah orang, kebutuhan air rerata untuk masak, mandi, cuci, kakus, dll. Pekerjaan ini memakan waktu dan tenaga tetapi bermanfaat bagi penyediaan air di pesantren, dapat diketahui kebutuhan air yang sesungguhnya.

Tahap tiga, peletakan pipa. Pasanglah pipa di tepi jalan utama agar mudah dipantau dan cepat diketahui jika ada yang pecah. Catat dan tandai jalan, sungai, jembatan, selokan, sawah, kanal, dll pada peta. Buatlah lajur pipa yang terpendek agar lebih murah dan pilihlah jenis pipanya. Pilih pipa yang relatif murah tetapi kuat, yaitu yang mampu menahan tekanan kerja air minimal 10 bar atau 10 atmosfer alias 100 meter kolom air (mka). Bahannya bisa PVC, baja, besi tuang, dll. Di perdesaan umumnya digunakan pipa PVC kecuali kasus tertentu yang terkait dengan kondisi lapangan yang berbatu, tanahnya labil, melewati sungai lebar, kanal, dll.

Tahap empat, operasi-rawat. Tahap akhir ini jauh lebih berat ketimbang pengerahan dana. Banyak SPAM di berbagai daerah akhirnya menjadi pipa tanpa air, tak terawat lantaran masyarakat tidak merasa ikut memilikinya. Tiada sense of belonging. Oleh sebab itu, SPAM sebetulnya bisa langgeng beroperasi kalau dirawat oleh semua orang, apalagi kalau berasal dari kerja keras dan keringat semua warga pesantren. Di sinilah pentingnya mengajak semua warga pesantren sejak awal ide diniatkan, perencanaan, pembelian pipa, konstruksi dan operasi-rawatnya.

\section{Teknologi Pengolah}

Ada beberapa unit pengolah tepat guna yang dapat diterapkan karena sederhana desainnya. Misalnya, DyGF (Dynamic Gravel Filter) yang terdiri atas 3 atau 4 bak filter. Setiap bak diisi gravel, dengan media kasar di kompartemen pertama dan berturut- 
turut media yang kecil di kompartemen terakhir. Air mengalir turun melewati setiap kompartemen. Ada juga Upflow Roughing Filter Seri (URFS). Karena kebanyakan akumulasi padatan terjadi di dasar filter dekat pipa pengurasnya, maka URFS ini lebih mudah dibersihkan.

URFL (Lapis) terdiri atas bak filter yang berisi multilapis media mulai dari yang media kasar di dasar bak hingga media halus di lapisan atas. Keuntungan URF Lapis ini ialah persyaratan ruangnya kecil dan biayanya rendah dibandingkan dengan HRF maupun URF Seri. URF Lapis sangat efektif untuk air yang rendah sampai medium kekeruhannya (<150 NTU). Juga bagus untuk air dari mata air yang telah bercampur dengan air sungai di sekitarnya dan keruh ketika hujan.

HRF (Horizontal Roughing Filtration) terdiri atas bak horisontal dengan 3 atau 4 ruang yang panjangnya bervariasi dan dipisahkan oleh sekat (baffle) dengan aliran horisontal. Setiap kompartemen diisi gravel, media kasar di kompartemen pertama dan berturut-turut media halus di kompartemen akhir. Keuntungan HRF karena panjang medianya besar dan kapasitas penyimpanan solid-nya juga besar maka frekuensi pembersihannya menjadi jarang. HRF ini cocok untuk mengolah air yang kekeruhannya tinggi. Tetapi HRF perlu lahan yang relatif lebih luas daripada URF.

Setelah diolah di unit Roughing Filter, air selanjutnya dialirkan ke Filter Pasir Lambat (Fipal atau Slow Sand Filter). Ada sejumlah kriteria desain yang dibuat oleh pakar air minum dan ditampilkan pada Tabel 1. 
Tabel 1 Perbandingan kriteria desain Slow Sand Filter oleh beberapa pakar.

\begin{tabular}{|c|c|c|c|c|}
\hline Kriteria Desain & $\begin{array}{l}\text { Standar } \\
\text { USA } \\
(1987)\end{array}$ & $\begin{array}{l}\text { Huisman } \\
\text { \& Wood } \\
(1974)\end{array}$ & $\begin{array}{l}\text { Visscher, } \\
\text { et al } \\
\text { (1987) }\end{array}$ & $\begin{array}{c}\text { Galvis, } \\
\text { et al } \\
(1988)\end{array}$ \\
\hline Periode desain (tahun) & - & - & $10-15$ & $8-12$ \\
\hline Periode operasi (jam per hari) & 24 & 24 & 24 & 24 \\
\hline Laju filtrasi (m/jam) & $0,08-0,24$ & $0,1-0,4$ & $0,1-0,2$ & $0,1-0,3$ \\
\hline $\begin{array}{l}\text { Media pasir: } \\
\text { - Tinggi awal }(\mathrm{m}) \\
\text { - Tinggi minimum }(\mathrm{m}) \\
\text { - Ukuran efektif }(\mathrm{mm})\end{array}$ & $\begin{array}{l}0,8 \\
- \\
0,30-0,45\end{array}$ & $\begin{array}{l}1,2 \\
0,7 \\
0,15-0,35\end{array}$ & $\begin{array}{l}0,9 \\
0,5 \\
0,15-0,30 \\
\end{array}$ & $\begin{array}{l}0,8 \\
0,5 \\
0,15-0,30 \\
\end{array}$ \\
\hline $\begin{array}{l}\text { Koefisien keseragaman: } \\
\text { a. Dapat diterima } \\
\text { b. Lebih disukai }\end{array}$ & $\begin{array}{l}- \\
\leq 2,5\end{array}$ & $\begin{array}{l}<3 \\
<2\end{array}$ & $\begin{array}{l}<5 \\
<3\end{array}$ & $\begin{array}{l}<4 \\
<3\end{array}$ \\
\hline Tinggi kerikil termasuk drainase $(\mathrm{m})$ & $0,4-0,6$ & - & $0,3-0,5$ & 0,25 \\
\hline Tinggi maksimum air supernatan (m) & 0,9 & $1-1,5$ & 1 & 0,75 \\
\hline Freebroad, ambang bebas $(\mathrm{m})$ & - & $0,2-0,3$ & 0,1 & 0,1 \\
\hline Luas permukaan maksimum $\left(\mathrm{m}^{2}\right)$ & - & - & $<200$ & $<100$ \\
\hline
\end{tabular}

Sumber: Sanchez et.al, 2006

Skema gavel filter-nya dapat dilihat pada Gambar 1. Inovasinya diperlihatkan pada Gambar 2 yang merupakan integrasi kedua unit filter tersebut dan diharapkan mampu mengolah air permukaan yang keruh menjadi jernih untuk keperluan pesantren.

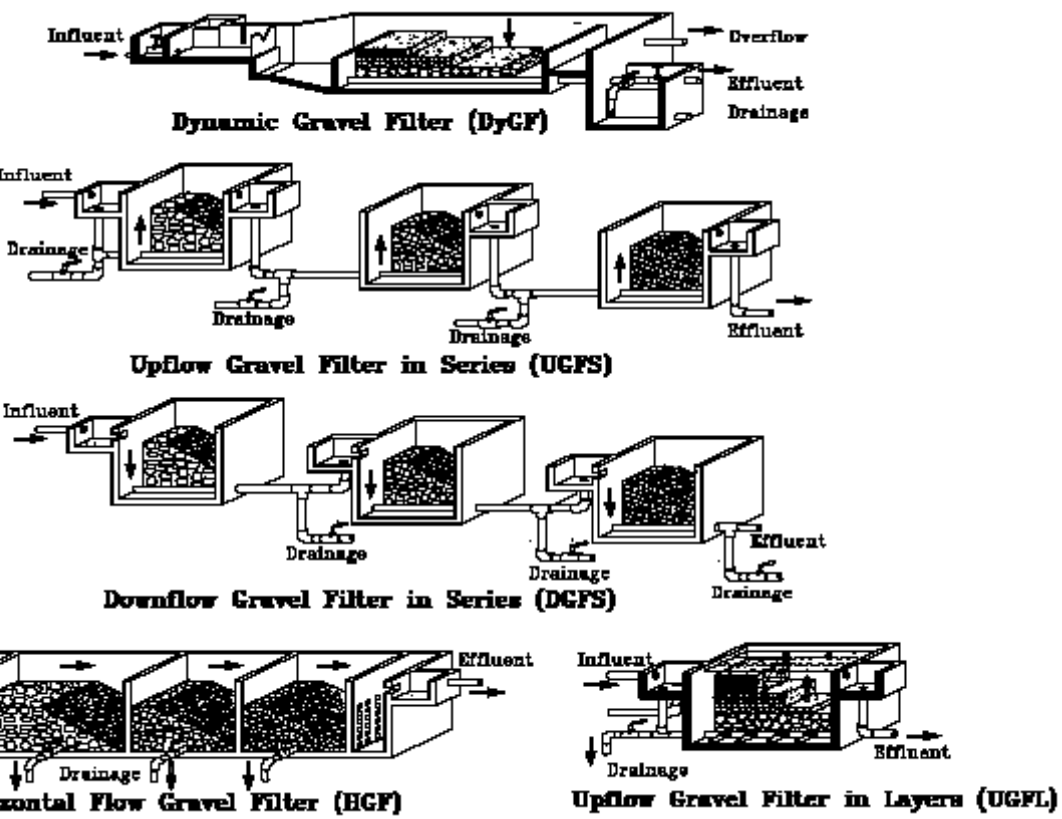

Gambar 1. Skema variasi Gravel Filter yang dijadikan pilot plant di Puerto Mallarino Colombia, Amerika Latin (Sanchez et.al, 2006). 


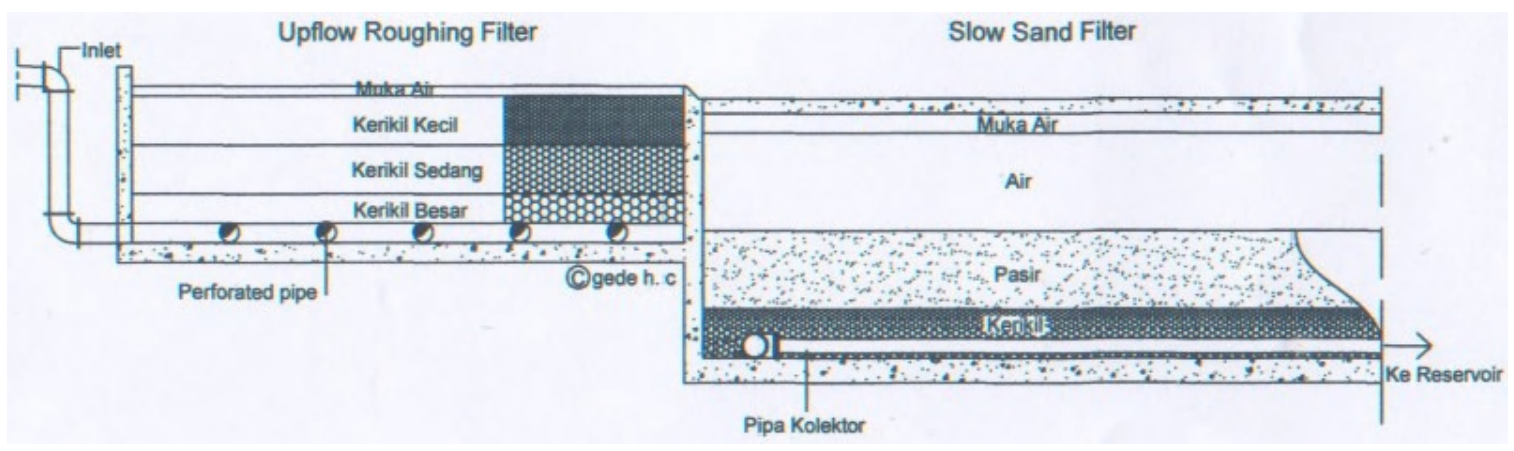

Gambar 2. Contoh inovasi URF dan SSF, serial unit tepat guna pengolah air minum, mampu mengolah air sungai berkekeruhan tinggi..

Data desainnya, data ini diperlukan untuk menghitung dimensi filter, ditulis di Tabel 2.

Data ini diambil dari disertasi doktor Gerardo Galvis (2002), pakar air minum dan pemimpin di CINARA, Colombia.

Tabel 2. Komparasi kriteria desain URF Lapis dan URF Seri.

\begin{tabular}{|c|c|c|}
\hline Parameter & URF Lapis & URF serial \\
\hline Laju filtrasi, m/jam & $0,3-1,0$ & $0,3-1,0$ \\
\hline $\begin{array}{l}\text { Diameter kerikil per ruang } \\
\text { * panjang }(\mathrm{m}) \text { dan diameter }(\mathrm{mm})\end{array}$ & $\begin{array}{l}\text { Satu ruang } \\
0,2-0,3(25-19) \\
0,2-0,3(19-13) \\
0,2-0,3(13-6)\end{array}$ & \begin{tabular}{l}
\multicolumn{1}{l}{ Tiga ruang } \\
$0,6-1,0(25-19)$ \\
$0,6-1,0(19-13)$ \\
$0,6-1,0(13-6)$
\end{tabular} \\
\hline${ }^{*}$ kerikil underdrain & $0,15-0,3(25-35)$ & $0,15-0,3(25-35)$ \\
\hline Tinggi air supernatan, di atas kerikil (m) & $0,1-0,20$ & $0,1-0,20$ \\
\hline Head statis utk menguras lumpur (m) & $>2,5$ & $>2,5$ \\
\hline Kecepatan pengurasan awal, m/jam & $>10$ & 10 \\
\hline
\end{tabular}

Sumber: Sanchez, 2006

\section{Mekanisme Filtrasi}

Seperti umumnya filter pasir, air umpannya masuk di antara butir pasir berukuran tertentu, biasanya kurang dari $0,35 \mathrm{~mm}$. Air ini melewati lapisan porus yang disebut parasitas (perviousness). Secara hidrolis, air umpan biasanya masuk dari atas filter (downflow) menerobos ruang antarbutir lalu dikumpulkan di bawah filter yang disebut sistem underdrain (kolektor). Laju filtrasinya rendah seperti tampak pada Tabel 1 dan Tabel 3 dan bergantung pada gradasi media filter dan kualitas air bakunya. 
Unit pengolah ini terdiri atas tangki, lapisan pasir, kerikil (gravel) sebagai penopang pasir, sistem underdrain untuk mengoleksi filtrat, dan pengatur aliran atau laju filtrasi. Satu keunggulan unit ini ialah tak perlu zat kimia (koagulan) dalam pengolahannya. Klorinasi pun hakikatnya tak perlu lagi. Walau demikian, agar ada upaya preventif maka Fipal biasanya dilengkapi dengan unit klorinasi. Itu sebabnya, unit ini termasuk murah biaya operasi-rawatnya, tidak ada kebutuhan energi untuk pompa dan kompresor sebagai mekanisme pencucian filter (scouring dan backwashing).

Sebelum dioperasikan, pada tahap awal operasinya, unit ini butuh beberapa minggu sampai pertumbuhan mikroba di biolapisnya dalam kondisi stabil. Di biolapis inilah banyak disisihkan koloid, SS, protozoa, dan bakteri, termasuk besi dan mangan. Setelah beberapa bulan beroperasi, headloss-nya mulai meningkat karena lapisan atasnya mulai kotor sehingga harus dibersihkan dengan cara disekop (scraped off). Yang disekop atau dibuang hanya lapisan atasnya sehingga biolapisnya masih tersisa dan ini akan cepat memulihkan kinerjanya. Siklus ini terus berulang sampai pada kedalaman minimum media yang diizinkan. Semua media sekopan tadi lantas dicuci di bak cuci pasir (sand washing place) dan setelah bersih dikembalikan lagi ke unit filternya.

\section{Konstruksi Filter}

Biasanya filter ini terdiri atas tangki, lapisan air, media filter, sistem drainase, dan kontrol aliran. Tangki berukuran kecil bisa dibuat dari bahan plastik, fibreglass dan yang besar biasanya berbahan beton. Jumlah tangkinya minimal dua buah agar yang satu dapat dibersihkan sementara satunya lagi tetap beroperasi. Jumlah total unit yang dibangun bergantung pada besar-kecilnya debit air yang diolah. Yang juga penting adalah tinggi taraf muka air di atas media filter. Beda tinggi ini memberikan head untuk proses filtrasi melewati pasir. Variasi kedalamannya antara $0,5-1,5 \mathrm{~m}$ atau $1-1,5 \mathrm{~m}$. 
Adapun medianya berupa pasir dengan ukuran efektif (effective size, ES) dan koefisien keseragaman (uniformity coefficient, UC) seperti ditulis di Tabel 3. Tebal medianya antara $1-1.5 \mathrm{~m}$ atau $0,6-1,2 \mathrm{~m}$. Data lain menyatakan, sebaiknya tebal minimumnya 0,8 m. Media pasir ini tidak boleh sembarangan tetapi memiliki karakteristik tertentu, yaitu diameternya antara $0,15-0,35 \mathrm{~mm}$, ES $=0,25 \mathrm{~mm}$ dengan UC kurang dari 2 atau 3. Pasir ini pun harus dicuci sampai bersih, tidak mengandung tanah, lempung, dan zat organik. Partikel yang sangat kecil (halus) akan mempercepat penyumbatan sehingga frekuensi pembersihannya menjadi sering. Pasir yang tidak seragam dapat mereduksi parasitas antarpasir sehingga memperlambat aliran air.

Setelah melewati lapisan pasir tersebut, air mengalir di lapisan kerikil (gravel) yang fungsinya sebagai penopang dan pencegah pasir agar tidak hanyut ke bagian outlet filter. Menurut kebiasaan desain di Eropa, spesifikasi kerikilnya terdiri atas tiga lapis, yaitu 2 - $8 \mathrm{~mm}, 8$ - $16 \mathrm{~mm}$, dan $16-32 \mathrm{~mm}$. Tentu saja diameter lainnya bisa saja diterapkan, bergantung pada keputusan desain dengan pertimbangan tertentu. Di bawah kerikil ini lantas dipasang sistem drainase (underdrain) atau kolektor air dengan pola jaringan pipa. Yang terakhir ialah kontrol aliran air. Pada filter besar, flowmeter (misalnya venturimeter) dipasang untuk memonitor aliran air. Aliran ini biasanya dinyatakan dalam liter per jam per m2. Debit akan berkurang seiring dengan penumpukan material di biolapis atau permukaan pasir. 
Tabel 3. Karakteristik umum Fipal dan Fipat.

\begin{tabular}{|l|l|l|}
\hline \multicolumn{1}{|c|}{ Karakter } & \multicolumn{1}{c|}{ Fipal } & \multicolumn{1}{c|}{ Fipat } \\
\hline Laju filtrasi & $1-\underline{4}-8 \mathrm{~m} 3 / \mathrm{m} 2 /$ hari & $100-475 \mathrm{~m} 3 / \mathrm{m} 2 / \mathrm{hari}$ \\
\hline Tebal media & $0,3 \mathrm{~m}$ koral; $1-1,5 \mathrm{~m}$ pasir & $0,5 \mathrm{~m}$ koral; $0,75 \mathrm{~m}$ pasir \\
\hline Ukuran pasir & $\begin{array}{l}\text { ES } 0,15-\underline{0,3}-0,35 \mathrm{~mm} \\
\text { UC } 2-\underline{2,5}-3 \text { (unstratified) }\end{array}$ & $\begin{array}{l}\text { ES } \geq 0,45 \mathrm{~mm} \\
\text { UC } \leq 1,5 \text { (stratified) }\end{array}$ \\
\hline Waktu operasi & $20-\underline{30-120 \text { hari }}$ & $12-\underline{24}-72$ jam \\
\hline Penetrasi kekeruhan & Hanya di permukaan pasir. & $\begin{array}{l}\text { Lebih dalam (semua media } \\
\text { dicuci dengan backwashing) }\end{array}$ \\
\hline Pengolahan awal & Roughing filter, Prased, Aerasi & $\begin{array}{l}\text { Perlu koagulasi, flokulasi dan } \\
\text { sedimentasi }\end{array}$ \\
\hline Cara pembersihan & $\begin{array}{l}\text { 1). Scraping off lapisan teratas } \\
\text { pasir lalu dicuci. }\end{array}$ & $\begin{array}{l}\text { Scouring mekanis, udara, air. } \\
\text { Kotoran dibuang dengan cara } \\
\text { upward backwash flow. } \\
\text { washer travelling on site. }\end{array}$ \\
\hline $\begin{array}{l}\text { Biaya konstruksi } \\
\text { Biaya operasi } \\
\text { Biaya depresiasi }\end{array}$ & $\begin{array}{l}\text { Relatif mahal } \\
\text { Relatif murah } \\
\text { Relatif rendah }\end{array}$ & $\begin{array}{l}\text { lebih murah } \\
\text { lebih mahal } \\
\text { lebih tinggi }\end{array}$ \\
\hline Persentase air pencuci & $0,2-0,6 \%$ air produksi & 1 - 6 \% air produksi \\
\hline
\end{tabular}

Sumber: Droste, 1997

Penerapan teknologi tepat guna di bidang pengolahan air minum ini diharapkan dapat membantu pesantren yang kesulitan memperoleh air bersih untuk kebutuhan seharihari. Dalam skala yang lebih besar, pesantren juga dapat membantu warga di sekitarnya dengan cara membagi-bagikan air olahannya lewat hidran umum yang dipasang di luar pesantren. Dengan demikian, eksistensi pesantren betul-betul dirasakan manfaatnya bagi masyarakat, tidak hanya di bidang keruhanian, tetapi juga dalam masalah sehari-hari. * 


\section{Daftar Rujukan}

1. Droste, Ronald, L Theory and Practice of Water and Wastewater Treatment, John Wiley \& Sons, Canada, 1997.

2. Galvis, Gerardo, Development and Evaluation of Multistage Filtration Plants, Dissertation of University of Surrey, United Kongdom, 1999.

3. Hendricks, Manual of Design for Slow Sand Filter, AWWA Research Foundation, USA, 1991.

4. Othman, A. H., Doi A. R., Islamic Principles of Environment and Development, Thought and Scientific Creativity, Vol. 3, No. 3., Malaysia, 1992.

5. Sanchez et.al., Multistage Filtration, IRC-CINARA, Colombia, 2006.

Dipublikasikan di jurnal ISTEK, Volume II, hlm. 301-310, Desember 2008. ISSN 1979-8911 